\title{
Fatal head injury from boxing: a case report from Greece
}

\author{
C Constantoyannis, M Partheni
}

Br J Sports Med 2004;38:78-79. doi: 10.1136/bjsm.2002.001123

The case is described of a fatal injury to a young amateur boxer. The number of deaths from boxing have decreased in recent years. However, new rules devised to promote safety, such as limitation of the number of rounds, mandatory use of safety head guards, and better medical control during the match, seem to be of limited value in preventing severe head injuries from boxing.

A ccording to tradition, the Olympic Games began in 776 $\mathrm{BC}$ in Greece; boxing is one of the oldest events, being added in 688 BC. Ancient boxing had fewer rules than the modern sport. Boxers fought, without rounds, until one of them was knocked out or admitted defeat by raising one or two fingers. The spectators often attempted to intervene when the match became life threatening for the boxer. Instead of gloves, ancient boxers wrapped leather thongs around their hands and wrists, which left their fingers free. ${ }^{1}$ A famous athlete of antiquity was Melanomas of Karia; he became famous for his many victories as a boxer. He was never injured and had never injured any of his opponents. Melanomas believed that to injure someone showed a lack of bravery. Spectators enjoyed watching as he defended himself against blows from his opponents without striking them. He eventually left his opponents so exhausted and frustrated that they could not hit him, and they would give up and admit defeat. The later Roman invention in 150 BC of the "caestus", a boxing glove reinforced with iron and lead, transformed the Greek art of boxing into an inhuman and deadly contest. ${ }^{12}$ The persistence of boxing related head injuries, despite new protective measures and regulations, spawns criticism of the continued practice of organised amateur and professional matches.

A total of 659 deaths from boxing between 1918 and 1997 have been recorded, with an average of nine a year. There appears to be a decreasing trend in the number of fatalities in more recent years. ${ }^{3}$ We here report another case of a fatal head injury resulting from amateur boxing in Greece.

\section{CASE REPORT}

An 18 year old man suffered multiple blows to the head during an amateur boxing match, and became progressively lethargic and finally comatose. He was transferred to the trauma centre after 25-40 minutes. He was haemodynamically stable, with a Glasgow coma scale of 7 and pupils that were bilaterally reactive. He arrived in the computed tomography department 25 minutes after his admission. The scans of his head showed a small left subdural haematoma, hemispheric oedema with midline shift to the right, and subarachnoid haemorrhage (fig 1). A neurosurgical resident and a senior neurosurgeon were present in the emergency department (this is common practice in our health service).

The patient's symptoms indicated parenchymal brain injury and cerebral oedema, so we decided to try conservative treatment with mechanical ventilation, intracranial pressure monitoring, mild hyperventilation, and intravenous mannitol ( $250 \mathrm{ml}$ given rapidly intravenously). The patient had been intubated before any treatment and then transferred to the intensive care unit one hour after his admission.

He remained stable under suppression, but after one hour and 40 minutes, he showed haemodynamic instability, increased intracranial pressure, and bilateral fixed pupils at $7 \mathrm{~mm}$. On examination, both oculocephalic responses and corneal reflexes were absent and no cough could be elicited. We used additional measures to control intracranial hypertension (200 mg mannitol rapidly administered intravenously; hyperventilation with $\mathrm{PCO}_{2} 27 \mathrm{~mm} \mathrm{Hg}$ ). His blood pressure remained $>90 \mathrm{~mm} \mathrm{Hg}$ throughout. We planned to perform a second computed tomographic scan when the patient was stable. However, he had a cardiac arrest 10 minutes after the previous episode. Resuscitation failed and finally he died.

\section{DISCUSSION}

The mechanism of injury to the brain during boxing is complex because it depends on both the effect of the direct impact of the gloved fist on the skull and the motion of the brain and skull in response to it. It is believed by Mawdsley and Ferguson ${ }^{4}$ that, at the time of the impact of the fist on the skull, there is a transient acceleration of the head. The skull moves faster than the brain because of the inertia of the latter, and, as the skull comes to rest, the brain continues to move. As a result, the brain impacts on bony ridges of the skull surface or on the edge of the dural attachment. Contusions and intraparenchymal haemorrhages may occur by this mechanism. These impact forces are said to be responsible for the symptoms and findings that neurosurgeons and neurologists call concussion. Stretching forces on the veins that cross the subdural space (bridging veins) result in the development of subdural haematoma, which is responsible for most deaths from boxing. Govons ${ }^{5}$ believes that an impact to the brain may damage the reticular activating system resulting in a decrease in consciousness.

Jordan and Campbell ${ }^{6}$ showed that the proportion of cerebral injuries in professional boxing is higher than in amateur boxing. In a prospective five month study of amateur boxers in Ireland, Porter and $\mathrm{O}^{\prime} \mathrm{Brien}^{7}$ noted only 33 acute mild head injuries in 281 partial or complete bouts. However, there is a good evidence that repeated brain injury, even though each individual injury produces minimal or unobservable immediate effects, causes chronic brain damage and encephalopathy. ${ }^{3-10}$

It seems that acute subdural haematoma with underlying brain oedema has the highest mortality $(60-90 \%) .{ }^{11}$ In our case, the cause of death seems to have been the loss of cerebral vascular autoregulation leading to hyperaemia and malignant cerebral oedema. ${ }^{12} 13$

The Association Internationale de Boxe Amateur (AIBA), which regulates all organised and amateur boxing, has added stipulations and rules in an attempt to promote safety, such as limitation of the number of rounds, compulsory wearing of 


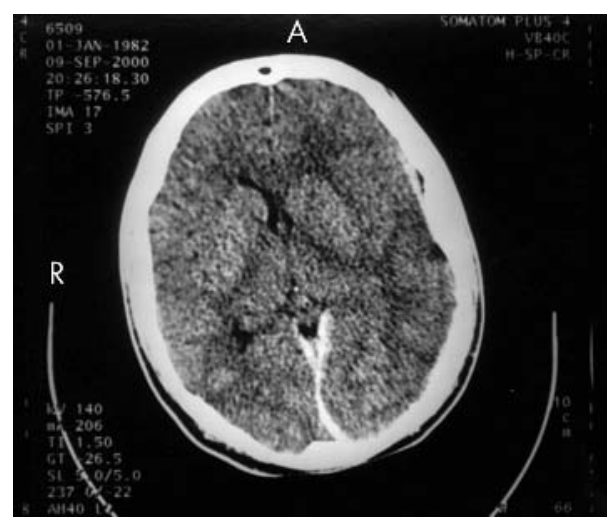

Figure 1 Computed tomographic scan showing a left small subdural haematoma, brain oedema with midline shift to the right, and subarachnoid haemorrhage.

safety head guards, and better medical control over boxers during the match.

However, the purpose of boxing is to render the opponent unconscious, producing temporary (or, rarely, permanent) brain damage. The risks of acute and chronic injury in boxing should be explained to the athletes and their families by doctors experienced in working with boxers. We emphasise that it is important that a person's choice should not only be free but also informed.

Young athletes may gradually be persuaded to turn their back on the sport. Despite the increasing number of ethical questions and the evidence on genetic predisposition to chronic traumatic encephalopathy in boxers, the question from neurologists and neurosurgeons remains: no more boxers or no more boxing related consequences? $?^{14} 15$

In our case, there were no disputes or claims from the relatives. ${ }^{16}$ The main purpose of this report is not to add to the rhetoric about safety and head injuries in boxing or to add to the ideological bias against boxing. Our concern is only about health.

\section{Authors' affiliations}

C Constantoyannis, P Meni, Patras School of Medicine, Patras, Greece

Correspondence to: Dr Constantoyannis, Patras School of Medicine, Patras, Greece; cconstantoyannis@yahoo.com

Accepted 11 February 2003

\section{REFERENCES}

1 Miller S. Ancient writers, papyri and inscriptions of the history, ideals of Greek athletics and games. Chicago: Ares Publishers Inc, 1979.

2 The Olympic games in ancient Greece. Athens: Ekdotiki Athenon, 1976.

3 Ryan AJ. Intracranial injuries resulting from boxing. Clin Sports Med 1998;17:155-68.

4 Mawdsley C, Ferguson FR. Neurological disease in boxers. Lancet 1963;19:799-801.

5 Govons S. Brain concussion and portuse: the knockdown blow of the boxing ring. Confin Neurol 1968;30:77-84.

6 Jordan B, Campbell E. Acute injuries among professional boxers in New York State: two year survey. Physician and Sports Medicine 1988;16:87-91.

7 Porter M, O'Brien M. Incidence and severity of injuries from amateur boxing in Ireland. Clin J Sport Med 1996;6:97-101.

8 Corsellis JAN, Brutan CJ, Freeman-Browne D. The aftermath of boxing. Psychol Med 1973;3:270-3.

9 Serel $M$, Jaros $O$. The mechanisms of cerebral concussion in boxing and their consequences. World Neurol 1962;3:351-8.

10 Unterharnscheidt F. A neurologist's reflections on boxing. V. Concluding remarks. Rev Neurol 1995;23:1027-32.

11 Wilberger JE, Harris M, Diamond DL. Acute subdural hematoma: morbidity, mortality and operative timing. J Neurosurg 1991;74:212-18.

12 Juul N, Morris GF, Marshall SB. Intracranial hypertension and cerebral perfusion pressure: influence on neurological deterioration and outcome in severe head injury. J Neurosurg 2000;92:1-6.

13 Kimelberg H. Current concepts of brain edema. J Neurosurg 1995;83:1051-9.

14 Jordan B, Relkin N, Ravdin L. Apolipoprotein E epsilon 4 associated with chronic traumatic brain injury. JAMA 1997;278:136-40.

15 Mc Crory P. Revisiting chronic traumatic encephalopathy. Br J Sports Med 2002;36:2.

16 Garfield J. Acute subdural hematoma in a boxer. Br J Neurosurg 2002; 16:96-101. 